\title{
Primary care clinicians' knowledge of oral cancer : a study of dentists and doctors in the North East of England
}

\author{
M. Greenwood, ' and R. J. Lowry, ${ }^{2}$
}

Objective To compare the knowledge of oral cancer and related issues of general dental and general medical practitioners (GDPs and GMPs).

Design A questionnaire was sent to 420 primary care clinicians, half to dentists and half to doctors. Responses to the questionnaire were analysed using odds ratios (OR) and 95\% confidence intervals (CI).

Results The response rate was $68.1 \%$ for GDPs and $71.9 \%$ for GMPs. Dental practitioners were significantly more likely to have diagnosed cases of oral cancer than medical practitioners $(\mathrm{OR}=$ $2.68,95 \% \mathrm{CI} 1.6,4.4)$. Important differences arose between the groups in terms of risk factor knowledge and clinical examination.

Conclusion This study demonstrates that whilst the knowledge level of both groups is generally good, there are some discrepancies. These relate mainly to risk factor knowledge and clinical examination techniques.

\footnotetext{
The oral cavity is usually easily accessible for examination and 1 thus offers the potential for opportunistic screening for intraoral cancer (ICD-9 141, 143 - 146). Previous studies have shown poor public awareness of the disease. ${ }^{1}$ For opportunistic screening to be effective, it is vital that primary care clinicians should be aware of the variety of presentations of malignant and premalignant disease. Treatment at an early stage improves prognosis. ${ }^{2}$ Schnetler ${ }^{3}$ and Scully ${ }^{4}$ have previously compared the relative performance of general dental practitioners (GDPs) and general medical practitioners (GMPs) in terms of their referral of patients with malignant oral disease, but studies into the relative core knowledge of these practitioner groups have not been carried out in this country.

Medical practitioners are given much less training in oral pathology than dental practitioners and therefore might be expected to have an inferior knowledge of oral cancer and related issues. Deficiencies in knowledge have implications for patient management and continuing professional education. The principal aim of this study was to assess the relative core knowledge of both groups of practitioner since both may see oral cancer patients.
}

\section{Methods}

The study was conducted prospectively using a questionnaire sent randomly to general medical and dental practitioners from family health service authority lists in and around Newcastle upon Tyne and on Teesside. A total of 420 questionnaires were sent out (half to

${ }^{1 *}$ Lecturer in Oral \& Maxillofacial Surgery. ${ }^{2}$ Consultant in Public Health Medicine, The Dental School, Framlington Place, Newcastle upon Tyne NE2 4BW ${ }^{*}$ Correspondence to: $M$. Greenwood

email: beryl.leggatt@ncl.ac.uk

REFEREED PAPER

Received 13.11.00; Accepted 02.07.01

(C) British Dental Journal 2001; 191: 510-512
GDPs, half to GMPs). Using standard methods it was calculated that at least 139 GMPs and 139 GDPs would be needed to give $90 \%$ power to the study. This level of power would detect a difference of $20 \%$ eg $40 \%$ of GMPs versus $60 \%$ of GDPs for a binary outcome measure, assuming a significance level of $5 \%$. The questionnaire (Appendix 1) had eight questions and it was found after an initial pilot that it took no longer than 10 minutes to complete. Responses to the questionnaire were analysed by calculating the odds ratios and $95 \%$ confidence intervals to illustrate any differences between the groups of practitioner. ${ }^{*}$ Non-responders were mailed a reminder.

\section{Results}

There were 143 returns for GDPs and 151 for GMPs, a response rate of $68.1 \%$ and $71.9 \%$ respectively. The year of first registration was similar in both groups of practitioner being 1970 - 1997 (median 1986) for the GDPs and 1970 - 1993 (median 1984) for the GMPs. Dental practitioners in this sample were significantly more likely to have diagnosed a case of oral cancer than medical practitioners (OR $=2.68,95 \%$ CI:1.6, 4.4) (Table 1). Diagnoses were confined to those made whilst working in primary care and were confirmed.

There were a number of important differences between GMPs and GDPs in relation to risk factors and clinical examination. GDPs were significantly more likely to list alcohol as a risk factor compared with the GMPs $(\mathrm{OR}=6.9,95 \% \mathrm{CI} 3.9,12.1)$. The proportion of GDPs and GMPs identifying smoking as a risk factor was $93.7 \%$ and $90.7 \%$ respectively. This difference was not significant $(\mathrm{OR}=$ $1.52,95 \%$ CI $0.6,3.6)$. GDPs were significantly less likely to state that they would examine all sites in the mouth equally than GMPs $(\mathrm{OR}=0.49,95 \%$ CI $0.3,0.8)$. GDPs showed a preference for examining areas relating to the tooth bearing or potential denture bearing tissues, rather than for some of the more high risk sites eg floor of mouth. GDPs were more likely to identify the various presentations of oral cancer and premalignant disease than medical practitioners ( $\mathrm{OR}=13.56$ and 25.73 respectively).

In most other ways, GMPs and GDPs were similar. Habits predisposing to oral cancer (principally betel nut chewing) were widely identified in both groups with no significant difference between them. Knowledge of treatment modalities was not significantly different between the groups and no practitioner in either group mentioned only one treatment modality. In terms of referral pathways, both groups of practitioner named oral and maxillofacial surgery (OMFS) in the majority of cases as the specialty to which they would refer a case of suspected oral cancer. The GDPs named oral medicine in $19 \%$ of cases and ENT was cited in $24 \%$ of cases by the GMPs as other specialties to which they would refer a case.

${ }^{\star}$ The odds ratio is calculated as the odds of identification of a particular factor by the GDP divided by the odds of identification of the same factor by a GMP. An odds ratio of 1 would indicate that both groups were the same. If a confidence interval included 1 or spanned 1 , the groups did not differ significantly 
Table I Comparison of GMPs and GDPs in various areas of oral cancer management and knowledge

\begin{tabular}{|c|c|c|c|c|}
\hline VARIABLE & GDP & $\underset{\%}{\text { GMP }}$ & $\begin{array}{l}\text { Odds } \\
\text { ratio }\end{array}$ & $\begin{array}{c}95 \% \\
\text { Confidence } \\
\text { interval }\end{array}$ \\
\hline $\begin{array}{l}\text { Practitioner group diagnosing } \\
\text { oral cancer }\end{array}$ & 72.0 & 49.0 & 2.68 & $1.6-4.4$ \\
\hline $\begin{array}{l}\text { Examination of all sites equally } \\
\text { versus specific sites }\end{array}$ & 51.1 & 68.2 & 0.49 & $0.3-0.8$ \\
\hline Referral specialty (OMFS) & 57.3 & 74.2 & 0.47 & $0.3-0.8$ \\
\hline $\begin{array}{l}\text { Treatment modalities (see text) } \\
\text { S,R versus } \\
\text { S,R+Chemo }\end{array}$ & $\begin{array}{l}\text { S,R } 27.9 \\
S, R, C 60.8\end{array}$ & $\begin{array}{l}\text { S,R } 64.9 \\
\text { S,R,C } 32.5\end{array}$ & $\begin{array}{c}0.21 \\
3.2\end{array}$ & $\begin{array}{l}0.1-0.3 \\
2.0-5.2\end{array}$ \\
\hline $\begin{array}{l}\text { Identification of smoking } \\
\text { as a risk factor }\end{array}$ & 93.7 & 90.7 & 1.52 & $0.6-3.6$ \\
\hline $\begin{array}{l}\text { Identification of alcohol } \\
\text { as a risk factor }\end{array}$ & 85.3 & 45.7 & 6.9 & $3.9-12.1$ \\
\hline $\begin{array}{l}\text { Identification of habits } \\
\text { as a risk factor }\end{array}$ & 60.8 & 50.3 & 1.53 & $1.0-2.4$ \\
\hline Presentation of oral cancer & 97.9 & 77.5 & 13.56 & $4 . I-45.3$ \\
\hline $\begin{array}{l}\text { Knowledge of premalignant } \\
\text { lesions }\end{array}$ & 95.8 & 47.3 & 25.73 & $10.7-61.9$ \\
\hline
\end{tabular}

*S = surgery, $\mathrm{R}=$ radiotherapy, $\mathrm{C}=$ chemotherapy

\section{Discussion}

It has been suggested that GMPs are less likely to diagnose oral cancer than dental practitioners, ${ }^{5}$ but other studies ${ }^{3,4}$ have disagreed with this. For appropriate, prompt referral to take place, the basic knowledge of a primary care clinician is a key factor in the process. Schnetler ${ }^{3}$ found that a GMP was more likely to diagnose tumours and refer the patient the same day compared with a GDP who, he found was not good at diagnosing tumours. Other reports ${ }^{6}$ have shown comparable delays between practitioner groups when arranging referrals.

A dental check up can incorporate inspection for malignant or premaligant lesions. In this study the GDPs showed a preference for examining areas relating to the tooth bearing or potential denture bearing tissues, rather than for some of the more high risk sites eg floor of mouth. This sort of pattern has been noted before. ${ }^{3}$ In a large but unrepresentative study of UK dentists in $1991,{ }^{7}$ the majority of respondents said that they routinely carried out screening of the oral mucosa for malignant and premalignant lesions. The reason for preferential examination of sites was unclear but may be related to the relative ease and familiarity of examining these sites. Difficulties exist in assessing certain at-risk individuals in the GDS because they may not routinely attend a dental practitioner. There is an established pattern of lower dental attendance in individuals over 65 -years-old, and smokers attend on a less regular basis than non-smokers. ${ }^{8}$ This is particularly significant since smoking can also be implicated in a variety of other dental and oral diseases. ${ }^{9}$ Since a GMP may be the only healthcare professional to see these patients, it has been suggested that continuing professional education in this field should be provided for primary care medical as well as dental practitioners. ${ }^{10}$

Smoking was well known to be a potential cause of oral cancer, but alcohol was implicated in only $45.7 \%$ of GMP's responses. This was a significant difference from the GDPs and its importance illustrates the fact that health education can only be optimised when all significant risk factors are understood by the healthcare professionals themselves. For effective primary prevention, although knowledge is clearly a very important part of the equation, there are other factors involved as well. Previous studies have shown that many dentists do not feel comfortable with the idea of counselling patients on matters such as smoking or alcohol cessation. ${ }^{11}$ In one study, however, ${ }^{12}$ the majority of dentists felt that they had a role in counselling of patients to stop smoking and excessive alcohol consumption. The same study showed that if a GMP advised a patient to stop smoking, $5-10 \%$ would stop, the figure being increased if the advice was reinforced, illustrating that counselling can have beneficial effects.

Chemotherapy was cited as a possible treatment modality for oral cancer by $60.8 \%$ of GDPs and $32.5 \%$ of GMPs. This form of treatment is not a primary treatment modality in this context and the fact that it was mentioned by some practitioners did not reflect accurate knowledge.

The GDPs were more knowledgeable about premalignant lesions and possible presentations of oral cancer than were the GMPs. As previously mentioned Schnetler ${ }^{3}$ and Scully ${ }^{4}$ found that GMPs were better at referring early and suggesting malignancy as a diagnosis, but the former found that when a delay did occur it was usually greater that when it occurred with a GDP referral. One possible explanation for this is that premalignant lesions may not be recognised as such by some GMPs. Likewise, the variety of potential modes of presentation of oral cancer itself were not in this study as well recognised by the GMPs compared with the GDPs. This finding is not entirely surprising, since a dental student receives undergraduate training in oral pathology, whereas most medical students have very little training in this area.

This study was conducted in the North East of England and the results may not necessarily translate precisely to the rest of the country. Certainly referral patterns may differ between regions caused by differences in the local availability of resources.

\section{Conclusions}

The study demonstrates that whilst GMPs and GDPs share a broad factual base knowledge, there are some discrepancies, especially in relation to risk factor knowledge and clinical examination techniques. Making sure there is parity between clinicians who may have an opportunity to diagnose a potentially curable malignancy is an important task for continuing professional development. Joint sessions with doctors and dentists may be of value in the future which would optimise resources and allow shared self improvement between the practitioner groups.

The authors thank Dr Nick Steen of the Newcastle Centre for Health Services Research for his help with the statistical analysis.

1 Horowitz A N, Nourjah P, Gift H C. US adult knowledge of risk factors and signs of oral cancer. J Am Dent Assoc 1995; 126: 39-43.

2 Speight P M, Morgan P R. The natural history of oral cancer and precancer. Community Dent Health 1993; 10: Supplement 131-41.

3 Schnetler J F C. Oral cancer diagnosis and delays in referral. Br J Oral Maxillofac Surg 1992; 30: 210-213.

4 Scully C, Malamos D, Levers B G H, Porter S R, Prime S S. Sources and patterns of referrals of oral cancer: role of general practitioners. $\mathrm{Br} \mathrm{Med} \mathrm{J}$ 1986; 293: 599-601.

5 Henk J M, Langdon J D. Clinical presentation and diagnosis. In Henk J M, Langdon J D (eds). Malignant tumours of the oral cavity. p 43. London: Edward Arnold, 1985.

6 Cooke B E D, Tapper-Jones L. Recognition of oral cancer - causes of delay. Br Dent J 1977; 142: 96-98.

7 Warnakulasuriya K A A S, Johnson N W. Dentists and oral cancer prevention in the UK: opinions, attitudes and practices to screening for mucosal lesions and to counselling patients on tobacco and alcohol use: baseline data from 1991. Oral Dis 1999; 5: 10-14.

8 Haughney M G J, Devennie J C, Macpherson L M D, Mason D K. Integration of primary care dental and medical services: a three year study. Br Dent J 1998; 184: 343-347.

9 Johnson N W, Bain C A. Tobacco and oral disease. Br Dent J 2000; 189: 200206.

10 Dawson C E, Bain M, McCall D, Macpherson L M D, Moos K F. Scottish needs assessment programme: Oral Cancer. Glasgow: Scottish Forum for Public Health Medicine, 1996.

11 McCann M F, Macpherson L M D, Binnie V T, Stephen K W. A survey of Scottish primary care dental practitioners' oral cancer-related practices and training requirements. Community Dent Health 2000; 17: 24-30.

12 Chestnutt, I G, Binnie V I. Training in the provision of smoking cessation advice in United Kingdom dental schools and schools of dental hygiene. J Inst Health Educ 1996; 34: 109-111. 


\section{RESEARCH \\ oral cancer}

\section{Appendix I Primary care clinicians' knowledge of oral cancer}

Confidential Questionnaire

I. What was your year of first registration?

2. Have you ever diagnosed a case of oral cancer (whilst working in primary care only) and diagnosis confirmed after referral?

Please tick one

Definitely

Possibly

No

Don't know

3. Which site(s) in the mouth would you pay particular attention to when looking for potentially malignant lesions?

Floor of mouth

Under the tongue

On back of the tongue

Please tick one

Hard palate

Soft palate

Fauces

Mucous membrane cheek/lip/gums

Oro-pharynx

All sites equally

Other

4. Which specialty would you refer a case (suspected or definite) of oral cancer to?

General Surgery

ENT

Plastic Surgery

Oral \& Maxillofacial Surgery

Oral Medicine

Other

Please specify
5. Which treatments are available for the treatment of oral cancer that you are aware of?

Surgery

Radiotherapy

Chemotherapy

Other

Please specify

6. Which risk factors do you know with regard to oral cancer?

Please list as many as you can, preferably in order of importance.

7. Oral cancer may present:

Please tick one or more

As a persistent ulcer

As an erosion

Red patch

White patch

Any of these

8. May any of the above lesions be premalignant?

A persistent ulcer

An erosion

Red patch

White patch

Any of these

Thank you very much.

Please return in the prepaid envelope 